primary branch while the compliant balloon can seal the aneurysm neck and temporarily occlude the secondary branch. Conclusion This device can improve the placement of devices, such as coils and a new generation of liquid embolics, into an aneurysm sac without blocking the parent vessel in the shortterm, nor leaving metal in the parent vessel long-term. A new stent-balloon device would allow neurointerventionalists a lessrestricted time window to deploy embolic devices and obtain a more complete aneurysm sac fill while concurrently limiting any protrusion or migration of the embolic devices downstream.

Disclosures O. Asgari: None. H. Sodawalla: None. T. Becker: None.

\section{E-229 ANEURYSM RECURRENCE IN ANTERIOR COMMUNICATING ARTERY ANEURYSMS TREATED WITH HYDROGEL COATED COILS COMPARED TO BARE METAL COILS}

J MacDonell*, N Field, P Entezami, A Boulos, J Dalfino, A Paul. Department of neurosciences and Experimental Therapeutics, Albany Medical College, Albany, NY

\subsection{6/neurintsurg-2020-SNIS.260}

Introduction/Purpose Anterior communicating artery aneurysms (ACoAAs) account for 30 to $37 \%$ of all intracranial aneurysms and are additionally the most common location of subarachnoid hemorrhages (SAH). ${ }^{1} 2$ Endovascular coiling has been shown to be a safe treatment option for patients with intracranial aneurysms but there remains concern regarding potentially higher recurrence and subsequently higher retreatment rates. Preliminary results from the hydrogel endovascular aneurysm treatment (HEAT) trial have demonstrated reduced recurrence rates in aneurysms treated with hydrogel coated coils. Hydrogel coated coils result in higher mean packing density however their effects on recurrence rates have yet to be elucidated. In this study we compare recurrence and retreatment rates in ACoAAs treated with hydrogel coated coils to those treated with bare metal coils.

Materials and Methods A retrospective chart review was done on all patients $>18$ years old with an ACoAA treated with endovascular coiling between 2014 and 2018. Follow up imaging included either magnetic resonance angiography (MRA) or cerebral angiography. Aneurysm recurrence was defined as any progress on the Raymond aneurysm occlusion scale on post-operative imaging. Treatment groups were divided into hydrogel coated coil or bare metal coil. Patients were categorized as hydrogel coated coil when $\geq 70 \%$ of the coil length was hydrogel coated. Patients with $<70 \%$ hydrogel coated coils were placed in the bare metal coil treatment group. Fisher exact test was used to determine statistical significance.

Results 84 ACOAA were treated with coil embolization between 2014 and 2018. Post-operative imaging was available for 68 patients. 26 patients were categorized into the hydrogel treatment group and 42 into the bare metal treatment group. Of the 68 patients, $50(74 \%)$ presented with aneurysm rupture. Sixty five percent $(17 / 26)$ of patients in the hydrogel group and $79 \%(33 / 42)$ patients in the bare metal group presented with subarachnoid hemorrhage $(p=0.26)$. Aneurysm recurrence was seen in $7.7 \%(2 / 26)$ of patients treated with hydrogel coated coils compared to $33.3 \%$ (14/42) of those treated with bare metal coils (p 0.03) (table 1). Sub-analysis of patients presenting with aneurysm rupture revealed decrease recurrence rates in patients treated with hydrogel coated coils at $5.9 \%(1 / 17)$ compared to patients treated with bare metal coils at 39.4\% (13/33) (p 0.01).

Conclusion Hydrogel coated coils may reduce recurrence rates in the treatment of both ruptured and unruptured ACoAAs.

\section{REFERENCES}

1. Cai W., et al., Anterior communicating artery aneurysm morphology and the risk of rupture. World Neurosurg 2018;109:119-126

2. Dehdashti AR, Chiluwal AK, Regli L. The implication of anterior communicating complex rotation and 3-dimensional computerized tomography angiography findings in surgical approach to anterior communicating artery aneurysms. World Neurosurg 2016;91:34-42.

Disclosures J. MacDonell: None. N. Field: None. P. Entezami: None. A. Boulos: None. J. Dalfino: None. A. Paul: None.

\section{E-230 COMPARISON OF PED AND FRED FLOW DIVERTERS FOR POSTERIOR CIRCULATION ANEURYSMS: A PROPENSITY- SCORE MATCHED COHORT STUDY}

${ }^{1} \mathrm{C}$ Griessenauer*, ${ }^{2} \mathrm{~A}$ Enriquez-Marulanda, ${ }^{3} \mathrm{~S}$ Xiang, ${ }^{3} \mathrm{~T}$ Hong, ${ }^{3} \mathrm{H}$ Zhang, ${ }^{4} \mathrm{P}$ Taussky, ${ }^{4} \mathrm{R}$ Grandhi, ${ }^{4} \mathrm{M}$ Waqas, ${ }^{5} \mathrm{~V}$ Tutino, ${ }^{5} \mathrm{~A}$ Siddiqui, ${ }^{5} \mathrm{E}$ Levy, ${ }^{2} \mathrm{C}$ Ogilyy, ${ }^{2} \mathrm{~A}$ Thomas, ${ }^{6} \mathrm{C}$ Ulfert, ${ }^{6} \mathrm{M}$ Möhlenbruch, ${ }^{7} \mathrm{~L}$ Renieri, ${ }^{7} \mathrm{~N}$ Limbucci, ${ }^{8} \mathrm{C}$ Parra-Fariñas, ${ }^{9} \mathrm{~J}$ Burkhardt, ${ }^{9} \mathrm{P}$ Kan, ${ }^{10} \mathrm{~L}$ Rinaldo, ${ }^{10} \mathrm{G}$ Lanzino, ${ }^{10} \mathrm{~W}$ Brinjikji, ${ }^{11} \mathrm{E}$ Müller-Thies-Broussalis, ${ }^{11} \mathrm{M}$ Killer-Oberpfalzer, ${ }^{12} \mathrm{C}$ Islak, ${ }^{12} \mathrm{~N}$ Kocer, ${ }^{13} \mathrm{M}$ Sonnberger, ${ }^{14} \mathrm{~T}$ Engelhorn, ${ }^{15} \mathrm{M}$ Ghuman, ${ }^{15} \mathrm{~V}$ Yang, ${ }^{16} \mathrm{~A}$ Salehani, ${ }^{16} \mathrm{M}$ Harrigan, ${ }^{17}$ I Radovanovic, ${ }^{17} \mathrm{~A}$ Dmytriw. ${ }^{1}$ Geisinger Health System, Danville, PA; ${ }^{2}$ Beth Israel Deaconess, Boston, MA; ${ }^{3}$ Capital Medical University, Bejing, China; ${ }^{4}$ University of Utah, Salt Lake City, UT; ${ }^{5}$ University of Buffalo, Buffalo, NY; ${ }^{6}$ University of Heidelberg, Heidelberg, Germany; ' University of Florence, Florence, Italy; ${ }^{8}$ St. Michael's Hospital, Toronto, ON, Canada; ${ }^{9}$ Baylor, Houston, TX; ${ }^{10}$ Mayo Clinic, Rochester, MN: ${ }^{11}$ Paracelsus University, Salzburg, Austria; ${ }^{12}$ Cerrahpasa Medical School, Istanbul, Turkey; ${ }^{13}$ Kepler Universitätsklinikum Linz, Linz, Austria; ${ }^{14}$ University Hospital Erlangen, Erlangen, Germany; ${ }^{15}$ Sunnybrook Health Sciences Centre, Toronto, ON, Canada; ${ }^{16}$ University of Alabama, Birmingham, AL; ${ }^{17}$ Toronto Western Hospital, Toronto, ON, Canada

\subsection{6/neurintsurg-2020-SNIS.261}

Introduction/Purpose Flow diversion is a popular endovascular treatment for cerebral aneurysms, but studies comparing different types of flow diverters are scarce. Here, we performed a propensity score-matched cohort study comparing the Pipeline Embolization Device (PED) and Flow Redirection Intraluminal Device (FRED) for posterior circulation aneurysms.

Materials and Methods Consecutive aneurysms of the posterior circulation treated at 25 neurovascular centers with either PED or FRED were collected. Propensity score matching was used to control for age, duration of follow-up imaging, adjunctive coiling, and aneurysm location, size, and morphology; previously ruptured aneurysms were excluded. The two devices were compared for the following outcomes: procedural complications, aneurysm occlusion, and functional outcome.

Results A total of 375 aneurysms of the posterior circulation were treated in 369 patients. The PED was used in 285 $(77.2 \%)$ and FRED in $84(22.8 \%)$ of procedures. Aneurysms treated with the PED were more commonly fusiform in morphology and larger in size compared to the FRED aneurysms. To account for these important differences, propensity score matching was performed resulting in 44 PED and FRED unruptured aneurysm pairs. There were no differences between the two devices in terms of occlusion status, functional outcome, and neurologic complications.

Conclusion Comparative analysis of PED and FRED for the treatment of unruptured posterior circulation aneurysms did not identify significant differences in aneurysm occlusion status 
at last follow-up, functional outcome, or neurologic complications.

Disclosures C. Griessenauer: None. A. Enriquez-Marulanda: None. S. Xiang: None. T. Hong: None. H. Zhang: None. P. Taussky: None. R. Grandhi: None. M. Waqas: None. V. Tutino: None. A. Siddiqui: None. E. Levy: None. C. Ogilvy: None. A. Thomas: None. C. Ulfert: None. M. Möhlenbruch: None. L. Renieri: None. N. Limbucci: None. C. Parra-Fariñas: None. J. Burkhardt: None. P. Kan: None. L. Rinaldo: None. G. Lanzino: None. W. Brinjikji: None. E. Müller-Thies-Broussalis: None. M. Killer-Oberpfalzer: None. C. Islak: None. N. Kocer: None. M. Sonnberger: None. T. Engelhorn: None. M. Ghuman: None. V. Yang: None. A. Salehani: None. M. Harrigan: None. I. Radovanovic: None. A. Dmytriw: None.

\section{E-231 IMPACT OF HOSPITAL-ACQUIRED COMPLICATIONS IN LONG-TERM CLINICAL OUTCOMES AFTER SUBARACHNOID HEMORRHAGE}

D Altschul* , S Unda, K Labagnara, J Birnbaum, M Wong, R De La Garza Ramos. Neurosurgery, Montefiore Medical Center, Bronx, NY

\subsection{6/neurintsurg-2020-SNIS.262}

Objective Patients with subarachnoid hemorrhage (SAH) usually have prolonged hospitalizations due to the need to closely monitor their neurological status. Therefore, these patients have higher risk of experiencing hospital-acquired complications (HACs), which can complicate their clinical course and recovery. However, there is no evidence on the impact of HACs of long-term clinical outcomes. We aimed to identify if HACs are independent risk factors for poor clinical outcomes at 12 to 18 months of follow-up.

Methods Retrospective analysis of 323 patients with SAH diagnosis from 2013 until June 2018. We collected patient-related factors (age, sex, BMI, ethnicity), comorbidities (hypertension, smoke status, diabetes, coronary heart diseases, prothrombotic diseases and hypercholesterolemia), clinical variables (HuntHess grade, modified Fisher grade, treatment, delayed cerebral ischemia), aneurysm characteristics (location, size) and HACs (pneumonia, DVT, ITU, EVD infections, sepsis, hyponatremia and acute respiratory distress syndrome). Poor outcomes were defined as $\mathrm{mRS} \geq 3$.

Results 204 patients were included in the primary analysis. 82 (40.2\%) experienced one or more HACs during their hospital course. Patients that developed HACs have significantly increased ICU $(12.1 \pm 6.6$ vs $24.3 \pm 23.6, \mathrm{p}<0.001)$ and hospital $(18.7 \pm 14.2$ vs $35.3 \pm 26.3, \mathrm{p}<0.001)$ length of stays. Moreover, patients with HACs had significant higher rates of delayed cerebral ischemia, non-routine discharge and poor outcomes at 90 days. 177 patients had complete followups at 12 to 18 months, HACs were independent risk factors for poor functional outcomes at 12 to 18 months after adjusting for demographic, comorbidities and clinical variables $[\mathrm{OR}=3.205,95 \%$ CI 1.231-8.347, $\mathrm{p}<0.017]$.

Conclusions HACs put patients at a higher risk of sustaining poor clinical outcomes 12 to 18 months after a SAH. Furthermore, HACs are significantly related with the occurrence of DCI, with non-routine discharge and 90-day poor functional outcomes.

Disclosures D. Altschul: 1; C; Medtronic. 2; C; Microvention, Stryker. S. Unda: None. K. Labagnara: None. J. Birnbaum: None. M. Wong: None. R. De La Garza Ramos: None.

\section{E-232 MID-TERM RESULTS OF ANEURYSM TREATMENT WITH THE NEW SURPASS EVOLVE FLOW DIVERTER: A MULTICENTER EXPERIENCE}

${ }^{1,2} \mathrm{E}$ Orru*, ${ }^{3} \mathrm{H}$ Rice, ${ }^{3} \mathrm{~L}$ De Villiers, ${ }^{1} \mathrm{~A}$ Wakhloo, ${ }^{3} \mathrm{G}$ Song Chia, ${ }^{2} \mathrm{~A}$ Qureshi, ${ }^{2} \mathrm{~T}$ Krings, ${ }^{2} V$ Pereira. ${ }^{1}$ Radiology - Division of Neurointerventional Radiology, Lahey Hospital and Medical Center, Burlington, MA; ${ }^{2}$ Joint Department of Medical Imaging - Division of Neuroradiology, Toronto Western Hospital, Toronto, ON, CANADA; 3 Interventional Neuroradiology, Gold Coast University Hospital, Southport, Australia

\subsection{6/neurintsurg-2020-SNIS.263}

Purpose Flow diverters have become a safe and well-accepted treatment option for intracranial aneurysms of most sizes in the anterior and posterior circulation. Surpass Evolve (SE, Stryker Neurovascular, Kalamazoo, Michigan, USA) is a new flow diverter that is available in large diameters $(2.5-5 \mathrm{~mm})$ and long lengths $(12-40 \mathrm{~mm})$, with high radial force and a high in-vitro flow diverting effect irrespective of the parent vessel tortuosity. This is secondary to a consistency in mesh density (15-30 pores $/ \mathrm{mm}^{2}$ ) and a high number of wires (4864, depending on the device length). SE can be deployed through an $0.027^{\prime}$ microcatheter, allowing easy navigation within tortuous anatomies. We describe device characteristics and mid-term results in the first patients treated with the SE for intracranial aneurysms.

Materials and Methods We included in this report all patients that underwent aneurysm embolization with the SE at two different institutions. Patients' data was prospectively collected in two databases and reviewed retrospectively. We included adult 